\title{
Editorial: Risk Management Models and Theories Volume II
}

\author{
Simon Grima ${ }^{1 *}$ and Eleftherios Thalassinos ${ }^{2}$ \\ ${ }^{1}$ Department of Insurance, Faculty of Economics, Management and Accountancy, University of Malta, Msida, Malta, ${ }^{2}$ Department \\ of Maritime Studies, University of Piraeus, Piraeus, Greece
}

Keywords: Risk models, Risk management, Risk measurement, Risk forecasting, Risk theories

Editorial on the Research Topic

\section{Risk Management Models and Theories Volume II}

The aim of this Research Topic_- "Risk Management Models and Theories Volume II", is to create a platform for authors to explore, analyze and discuss current and innovative financial models and theories that firms use/prescribe to determine, measure, monitor, forecast, and manage risk in the face of disruptors, such as the increased use of artificial intelligence and technology, change in regulations, climate change, etc.

Since the topic of Risk Management is quite vast, contributions in this second issue are again related to various areas. One of these areas explored a new nonparametric estimate of the risk-neutral density with applications to variance swaps. The authors here suggested that Estimates of risk-neutral densities of future asset returns have been commonly used for pricing new financial derivatives, detecting profitable opportunities, and measuring central bank policy impacts. They develop a new nonparametric approach for estimating the risk-neutral density of asset prices and reformulate its estimation into a double-constrained optimization problem and evaluate their approach using the S\&P 500 market option prices from 1996 to 2015. With this comprehensive cross-validation study

OPEN ACCESS

Edited by: George Lisi,

Brown University, United States

Reviewed by:

Ivaylo Ivanov,

Georgia State University, Atlanta, United States

Patrick Loria,

Yale University, United States

*Correspondence: Simon Grima simon.grima@um.edu.mt

Received: 05 March 2021 Accepted: 12 May 2021 Published: 25 May 2021

Citation:

Grima S and Thalassinos E (2021) Editorial: Risk Management Models and Theories Volume II.

Front. Appl. Math. Stat. 7:676404. doi: 10.3389/fams.2021.676404 they demonstrate that this approach outperforms the existing nonparametric quartic B-spline and cubic spline methods, as well as the parametric method based on the normal inverse Gaussian distribution.

Another author looks into the effect of banking efficiency, regulation and operations on performance of banks in South Asia. They use a dynamic correlated model approach to determine how the bank or industry-specific variables like banking regulation, banking efficiency, and banking operations affect non-performing loans in South Asia. To achieve this objective this study has employed robust 1st and 2nd generation Unit root tests, CIPS test, PMG and Dynamic Correlated Model approach on the panel data set of selected South Asian countries from 1995 to 2019, to avoid the implications of Cross-sectional dependency on the result analysis. The finding reveal that loose banking operations, lower exchange rate, and volatile interest rate have a significant positive relationship with non-performing loan whereas lower banking efficiency have a significant negative relationship with non-performing loans. Moreover, the author confirms the importance of cross-sectional dependencies in achieving more accurate and robust results.

The third article relates to calibrating and simulating copula functions in financial applications. With this article they aim to describe some simple statistical procedures currently employed to calibrate the copula functions to the financial market data. The authors assert that copula functions can be utilized in financial applications to determine the dependence structure of the financial asset returns in the portfolio and note that empirical evidence has proved the inadequacy of the multinormal distribution, traditionally adopted to model the financial asset returns distribution. They inform that copula functions can be employed in a flexible way for building efficient algorithms and 
to simulate a more adequate distribution of the financial assets. Furthermore, they present some useful methods for choosing which copula function better fits the real financial data, illustrating this with some algorithms to simulate random variates from certain types of copula functions and, for example purposes, they apply this to two important Italian equities. They show how to generate efficient Monte Carlo scenarios of equity log-returns in the bivariate case using different types of copula functions.

The fourth and final research article in this chapter relates to the asymmetric effect of the panic Index on cryptocurrencies. The author highlights the Covid-19 pandemic as the first major crisis facing cryptocurrencies. She demonstrates that news about epidemics affects investors' decisions and that there is a relationship between the panic index created from the news about the Covid-19 pandemic and the three major cryptocurrencies. Moreover, she shows that positive shocks in the panic index are the cause of negative shocks for all cryptocurrencies, demonstrating that an increase in the panic index cause the value of Bitcoin, Ethereum, and Ripple cryptocurrencies to decrease and that cryptocurrencies acted similarly to other financial assets during this pandemic period.
As can be noted from the above paragraphs, the contributions and findings of the second issue of this topic are quite focused around the area of finance and related to studies of current practices, tools, techniques and financial instruments used by the Risk Manager to manage identified exposures to risks. Therefore, the issue is aimed at the interest of academics and practitioners in this field.

\section{AUTHOR CONTRIBUTIONS}

All authors listed have made a substantial, direct, and intellectual contribution to the work, and approved it for publication.

Conflict of Interest: The authors declare that the research was conducted in the absence of any commercial or financial relationships that could be construed as a potential conflict of interest.

Copyright (c) 2021 Grima and Thalassinos. This is an open-access article distributed under the terms of the Creative Commons Attribution License (CC BY). The use distribution or reproduction in other forums is permitted, provided the original author(s) and the copyright owner(s) are credited and that the original publication in this journal is cited, in accordance with accepted academic practice. No use, distribution or reproduction is permitted which does not comply with these terms. 